InFestasi

Vol. 17 No. 1 Juni 2021

Hal. 55-64

\title{
Analysis and Design of Data Governance at the Financial Services Authority
}

\author{
Desta Arisandi ${ }^{1}$ Tubagus Muhamad Yusuf Khudri ${ }^{2}$ \\ ${ }^{1,2}$ Universitas Indonesia, Indonesia
}

\section{A R T I C L E \\ I N F O R M A T I O N}

Received 27 April 2021

Revised 10 June 2021

Publish 30 June 2021

Keywords:

Data governance, financial services authority, data management association

DOI:

https://doi.org/10.21107/infestasi.v17i1.10515

\begin{abstract}
A B S T R A C T
This research is a case study conducted at the Financial Services Authority on the implementation of a data governance framework based on the model from The Data Management Association in 2017. The purpose of this study is to produce a data governance framework in managing integrated Financial Services Sector data. This study uses a qualitative approach in describing data governance activities. The research instruments were interviews, questionnaires, and content analysis. The results show that data governance frameworks provide guidelines for various parties to act in accordance with the strategies that have been developed. Data governance program at the Financial Services Authority requires improvements in the form of establishing a data governance charter, assessing maturity levels, defining the operational framework, and adjusting the roadmap. In addition, it is also necessary to form a change management team, create a mechanism for handling data problems, and develop supporting tools for data governance programs.
\end{abstract}

\section{INTRODUCTION}

One of the benefits obtained by the Financial Services Authority (FSA) in using technological innovation is the ability to maximize the use of data reported by financial institutions. Based on Law Number 21 of 2011 concerning the Financial Services Authority, FSA was formed to be able to implement an integrated regulatory and supervisory system for all activities in the Financial Services Sector (FSS) which includes the banking, capital market, and Non-Bank Financial Industry (NBFI) sector. Based on the mapping carried out by FSA in 2018, in carrying out its functions, FSA received around 554 mandatory reports submitted by financial institutions with various data structures and formats. Several types of documents are form-based, excel, words, portable document format, comma-separated values, text, extensible business reporting language, and others. The large amount of data and various data formats received by FSA can cause problems in data management. These problems arise as a result of different policies and procedures, variations in reference data, data integration, and application development with similar functions.

Literature study approach has been widely used in research to identify the need for a data governance framework to address these data management problems, however, only a few studies have conducted case studies on data governance (Jim \& Chang, 2018). Literature studies on data governance frameworks also provide different results in the discussion areas, however, the topics of discussion include policies, standards, organizations, processes and technology (Jim \& Chang, 2018; Panian, 2010; Weber, Otto, \& Österle, 2009). This research was conducted in order to provide an integrated FSA data governance framework as a guide for the FSA in improving the quality of the data and information produced to support the implementation of the duties and functions of the FSA. This research is also to fill the gaps of previous research that uses a literature approach that focuses on the conceptual aspects of data governance, thereby confirming the activities and dimensions of data governance that can be used in an organi-

*Corresponding author: arisandi.desta@gmail.com 
zation.

The integrated FSS data governance framework built using model developed by The Data Management Association (DAMA) in 2017 will have an important role in improving the quality of data held by FSA. Good quality data will be used to produce information that is useful in making regulations, policies, monitoring activities, granting permits, coaching, as well as educating and protecting consumers who use financial services in Indonesia.

\section{LITERATURE REVIEW}

Each year, the quantity of data generated and stored by the organization has increased significantly. Policies and procedures are needed to avoid data erroneous, incomplete, non-renewable, and ensure data quality can produce useful information in supporting operations and strategies. Information becomes useful for the company if it has characteristics: relevant, reliable, complete, timely, understandable, verifiable and accessible (B Romney, 2018). Data governance helps organizations to ensure that their data is managed properly, based on good policies and practices (Ladley, 2019).

Data governance initiatives help improve data quality in the Kenya Health Professionals Authority by identifying data as assets and initiating data quality management mechanisms. In addition, data control, awareness, support and funding are needed for data governance initiatives (Were, 2016). At the strategic level, there should be a data governance steering board responsible for driving policy, aligning with business, and reviewing budgets for program initiatives (Cheong \& Chang, 2007).

Although many repeated studies have been carried out to explore the need for a data governance framework, however, there are three data governance models that can be used by organizations in implementing data governance programs: the model from The Data Management Association (DAMA) 2017, the model from The Data Governance Institute (DGI) in 2004, and the model from the International Business Machines Corporation (IBM) in 2008 (Al-Ruithe, Benkhelifa, \& Hameed, 2019). DAMA datagovernance framework (2017) divides data governance activities into three activities: planning, controlling, and operations. Furthermore, these activities are categorized into four groups of activities: defines data governance in an organization, define a data governance strategy, implementing data governance, and embed data governance.

\section{RESEARCH METHOD}

This research was conducted by making designs, collecting data, analyzing data, then making research conclusions. Research conclusion is based on the analysis of questionnaire, interview, and content analysis. The questionnaires were distributed to two senior analysts and two junior analysts that work for the integrated data and information management function at the FSA, that is the Integrated Data and Statistics Management Group (GDST). Questionnaire is used to calculate the average implementation score of the integrated FSS data governance activities, as well as to support the building of integrated FSS data governance framework in the FSA.

Interviews were conducted in September 2020 with two senior analysts who understand the implementation of the integrated FSS data-governance program. Open questions are used to find out how the data governance conditions are, the strategies in data governance, the support of various parties, policies, resources used, data governance implementation mechanisms and other questions that are relevant in developing an integrated FSS data governance framework. The results of the questionnaires and interviews were complemented with content analysis of documents related to data governance at FSA. Documents collected include strategic documents, annual reports, performance reports, policy documents, work plans, and other reports. This research was conducted based on the model depicted in the following figure: 


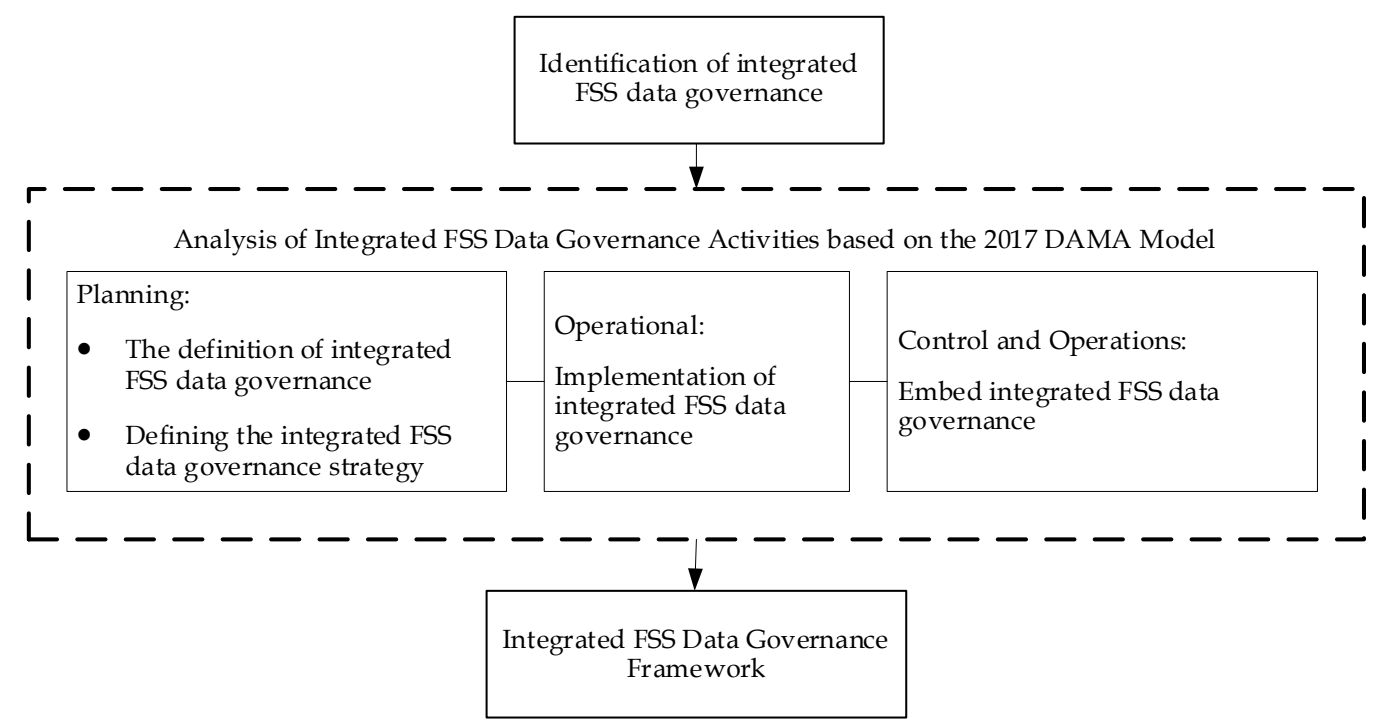

Figure 1 Research Framework

In this study, the analysis of all data governance activities was carried out based on the model from DAMA (2017). The stages of analysis in this study consisted of several activities. The first step is to identify the integrated FSS data-governance program. It will cover several data governance areas: human resources, technology, data management processes and policies in the FSA. The second step is to assess data governance activities. It is carried out by calculating the score for the implementation of integrated FSS data-governance based on a questionnaire. The next step is the result review based on identification and analysis of data governance activities. Then, we design an integrated FSS data governance framework in the FSA, that can provide suggestions and input for improving data governance program.

\section{RESULT AND DISCUSSION}

Data management unit at FSA is divided into three supervision areas: banking, capital market, and non-bank financial supervision. Each data manager in the supervision area has platform, provisions and guidelines for processing data. The following figure describes the flow of the FSS data management process at FSA:

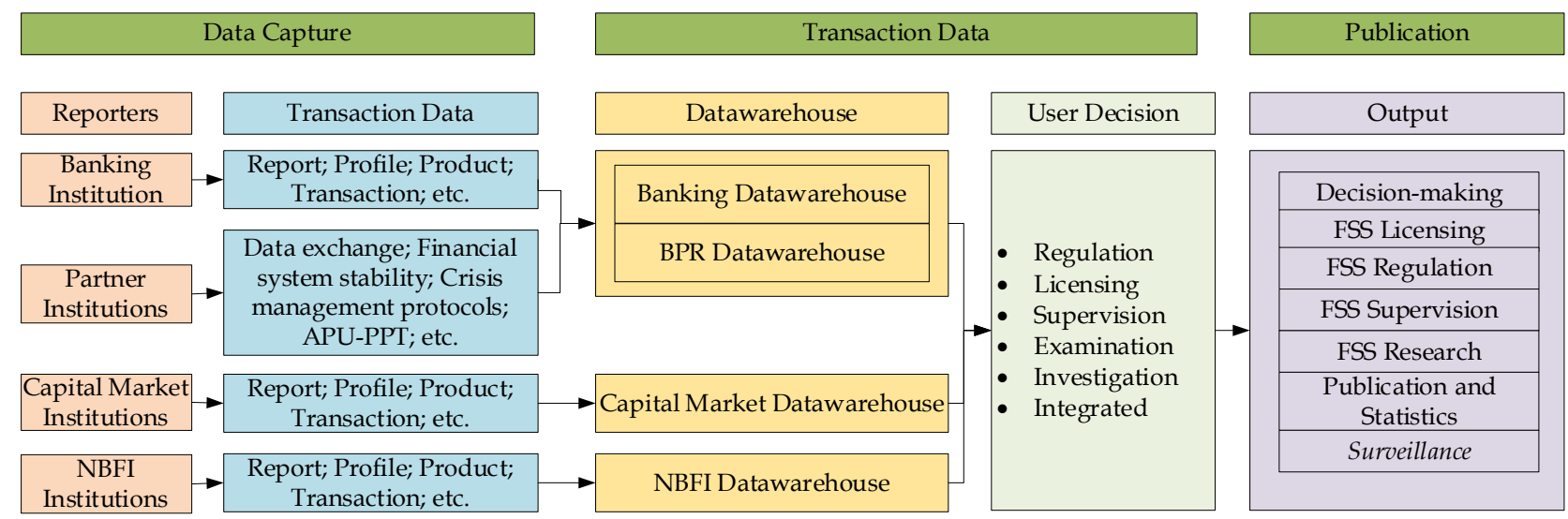

*Source: FSA (2020), has been reprocessed

Figure 2. Data Processing at FSA 
However, the integrated FSS data management function is carried out by Strategic Management 1 with the following organizational structure:

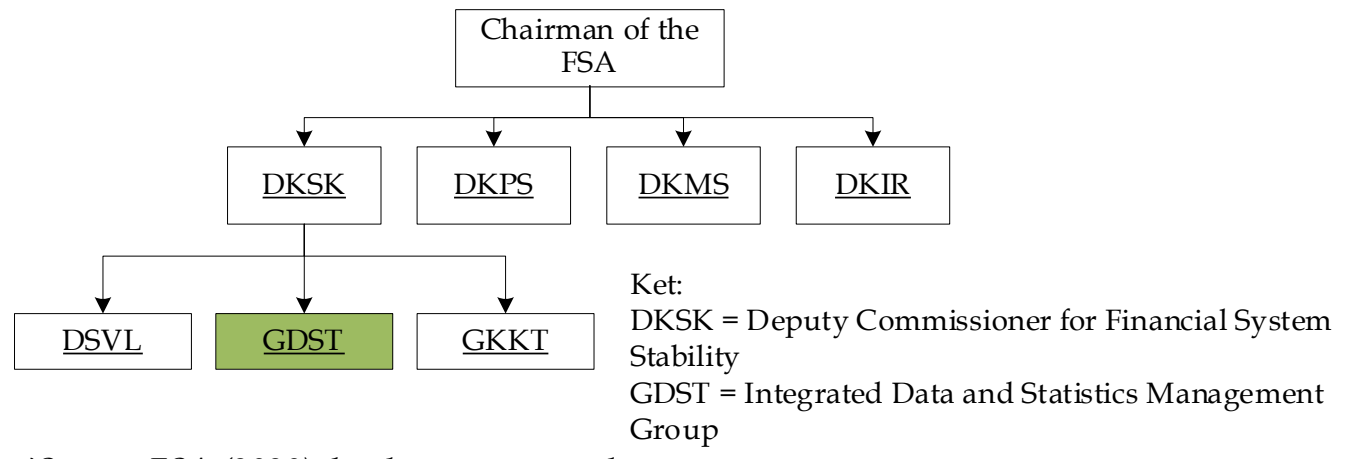

*Source: FSA (2020), has been reprocessed

Figure 3. Integrated FSS Data Management Organizational Structure

The existing technology infrastructure and information system applications are built, used and operated in each area of supervision. The value chain of the data management information system application that is built into the data processing flow can be seen in Figure 4 below:

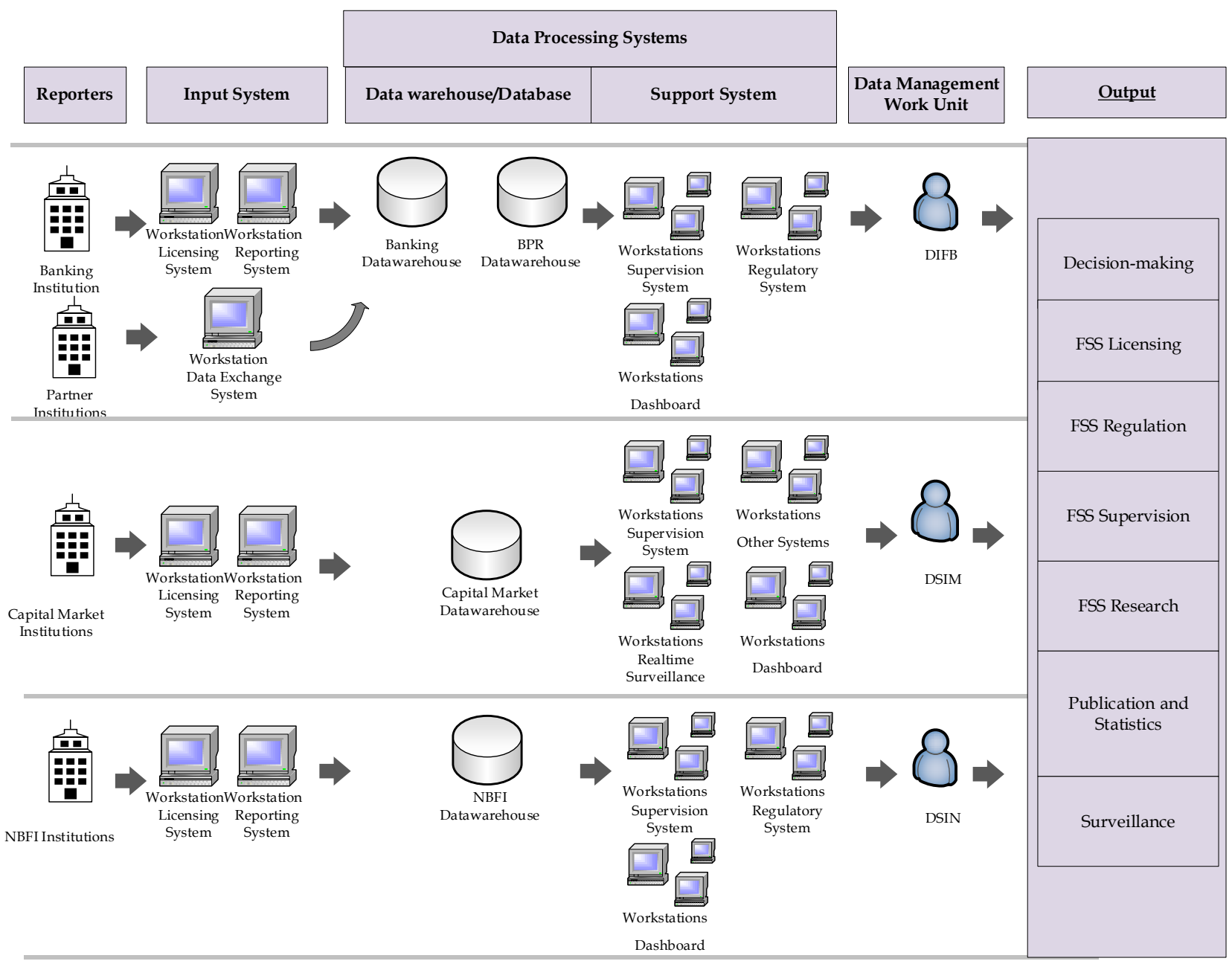

Source: FSA (2020), has been reprocessed

Figure 4. Value Chain of FSA Data Management Information System Application 
Based on the results of the mapping carried out by FSA in 2018, there are around 66 information system applications used in the data processing flow as shown in Figure 5 below:

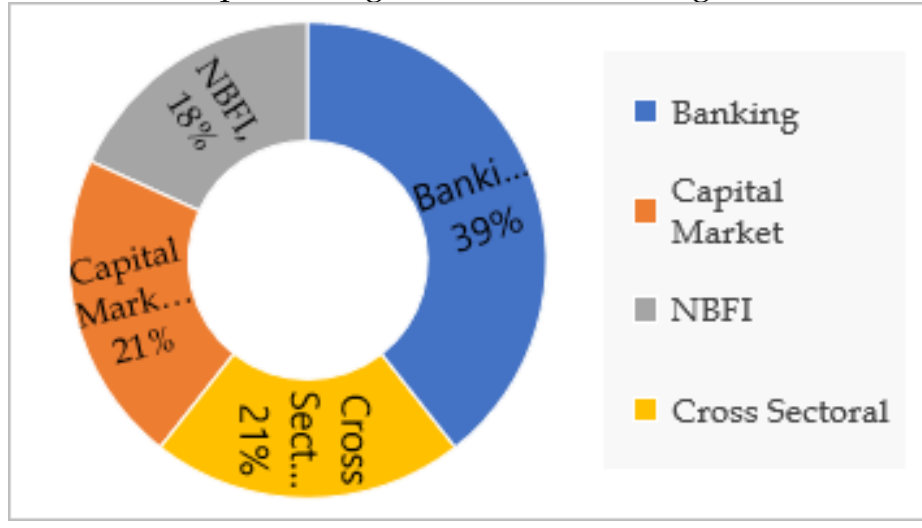

*Source: FSA (2020), has been reprocessed

Figure 5 Number of Applications Based on the Field of Supervision

Overall, the majority of FSA's information system applications are used for reporting activities (41\%) and supervisory activities (24\%). To support information technology-based supervision, FSA is developing supervisory technology and regulatory technology. Furthermore, when developing information system applications, FSA considers about user specifications, costs incurred, and their effects on many parties. These raise impact about the need for adjustments to the FSS reporting process, especially in relation to the form of reporting, reporting media, and the format of submission.

FSA has several data management rule that follow best practice and information system management standards. Policies related to data management are concerning about information system management, confidential information, information system security, application development, and archive management. In other hand, the number of employees and qualifications in running data management tasks is currently limited. There are 9 employees who work for integrated FSS data management function. The average of age is 38 years, which have an undergraduate education background $(67 \%)$ in economics $(78 \%)$.

Calculation of the score for the implementation of data governance activities at FSA is based on the DAMA model (2017) as in table below:

Table 1. Calculation of the Average Implementation of Integrated FSS Data-Governance Activities

\begin{tabular}{|c|c|c|c|c|}
\hline \multirow[t]{2}{*}{ No. } & \multirow[t]{2}{*}{ Sub-activities } & \multicolumn{3}{|c|}{ Implementation } \\
\hline & & Score & $\begin{array}{l}\text { Max } \\
\text { Score }\end{array}$ & $\%$ \\
\hline 1 & develop a data governance strategy & 16 & 20 & $80,0 \%$ \\
\hline 2 & carry out a readiness assessment & 13 & 20 & $65,0 \%$ \\
\hline 3 & conduct business alignment and discovery & 9 & 12 & $75,0 \%$ \\
\hline 4 & develop organizational touch points & 19 & 20 & $95,0 \%$ \\
\hline 5 & $\begin{array}{l}\text { defines the operational framework for data gov- } \\
\text { ernance }\end{array}$ & 3 & 7 & $42,9 \%$ \\
\hline 6 & develop goals, principles, and policies & 5 & 16 & $31,3 \%$ \\
\hline 7 & guarantee data management projects & 7 & 12 & $58,3 \%$ \\
\hline 8 & tie into change management & 2 & 8 & $25,0 \%$ \\
\hline 9 & tie into issue management & 7 & 12 & $58,3 \%$ \\
\hline 10 & assess compliance requirements & 8 & 11 & $72,7 \%$ \\
\hline 11 & $\begin{array}{l}\text { provide support for data-related standards and } \\
\text { procedures }\end{array}$ & 1 & 12 & $8,3 \%$ \\
\hline 12 & develop business glossaries & 10 & 12 & $83,3 \%$ \\
\hline 13 & coordinate with the architectural group & 8 & 12 & $66,7 \%$ \\
\hline
\end{tabular}




\begin{tabular}{lllll}
\hline $\mathbf{1 4}$ & provide support for the valuation of data & 1 & 4 & $25,0 \%$ \\
\hline $\mathbf{1 5}$ & embed data governance & 3 & 8 & $37,5 \%$ \\
\hline & Total & $\mathbf{1 1 2}$ & $\mathbf{1 8 6}$ & $\mathbf{6 0 , 2} \mathbf{0}$ \\
\hline
\end{tabular}

*Source: Processed data ,2020

Through the Decree of the FSA Board of Commissioners Number KEP-2/D.02/2018, FSA has determined the FSA Information System Design (RBSI) for 2018-2022. The FSA-RBSI describes the condition of the information system to be achieved in 2022, both from the business aspects, data management, application management, technology management, and principles. FSA-RBSI is prepared based on the destination statement of the FSA, directions from members of the Board of Commissioners, and also considers the needs of units in the FSA. The Head of the Information System Management Department (DPSI) reports to the deputy chairman of the FSA about any progress of the work of the FSARBSI. The following figure shows the FSA-RBSI for 2018-2022:
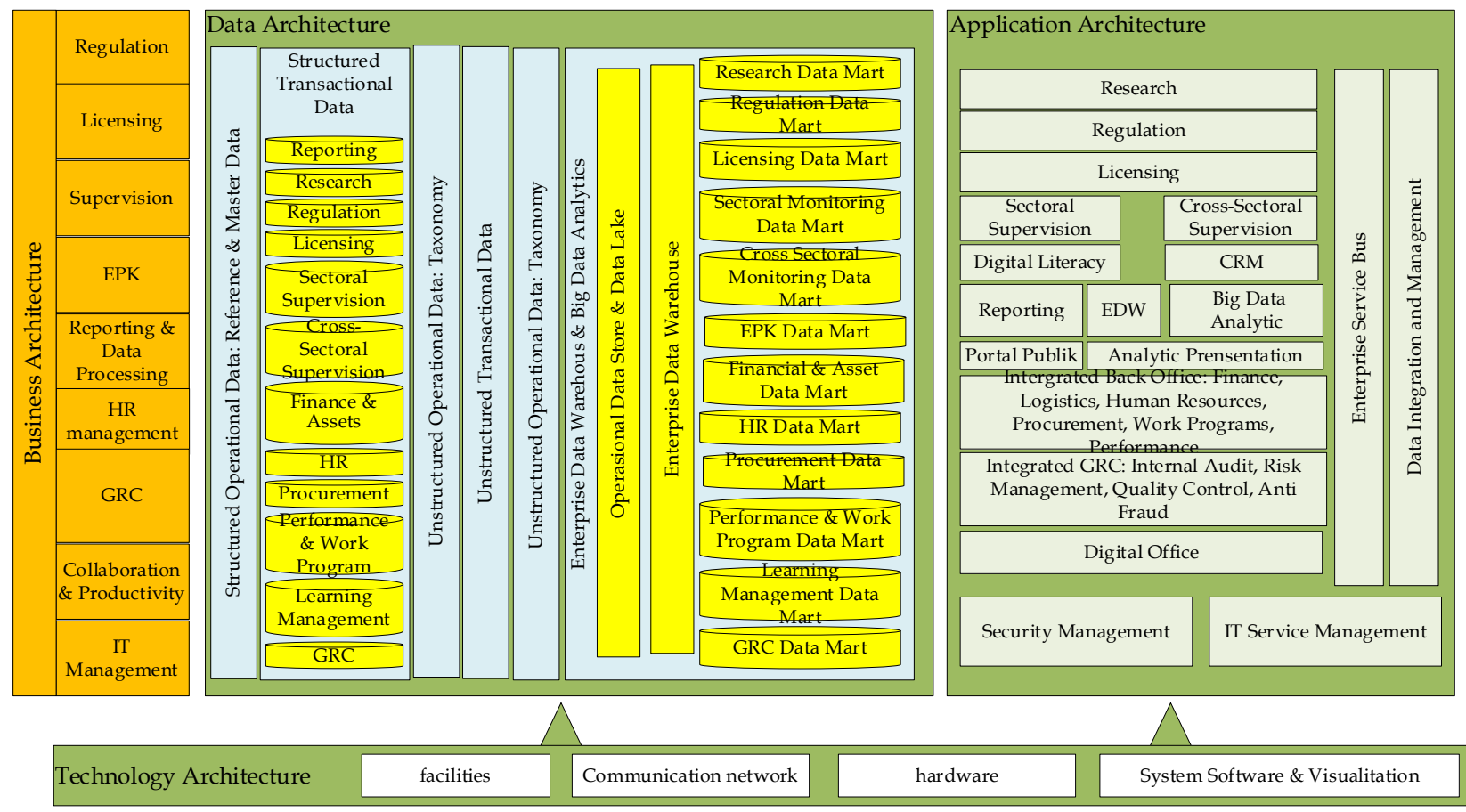

Figure 6. Design of the Financial Services Authority Information System

To achieve the expected output, it is necessary to define data governance strategy that should be outlined in the data governance charter. Currently, the vision, mission and principles of integrated FSS data management have not been included in the data governance charter. In 2018, the FSA has conducted a gap analysis regarding the current state of the FSS data management compared with the conditions expected to occur in 2022, using an independently developed method. FSA has identified benefits derived from integrated FSS data governance program. For example, the use of master data management can accelerate the fit and proper process and minimize missed or unrecorded data, thereby reducing the risk of incorrect data. Integrated FSS data-governance requires coherence from various aspects. Support needed includes: technology infrastructure, application development, data quality program, data management policies, procedures, standards, funding, culture changes, and organizational changes.

The existing operation of FSS data governance has impact on the length of time required to perform data processing. The existence of a data governance committee has not been formally defined in supporting FSS data management operations. To illustrate the relationship between data governance program initiatives and the work carried out by various parties, integrated FSS data-governance program 
requires an operational framework so that it can maintaining data quality, implementing policies, and managing data. Proposed operational framework shown in the following figure:

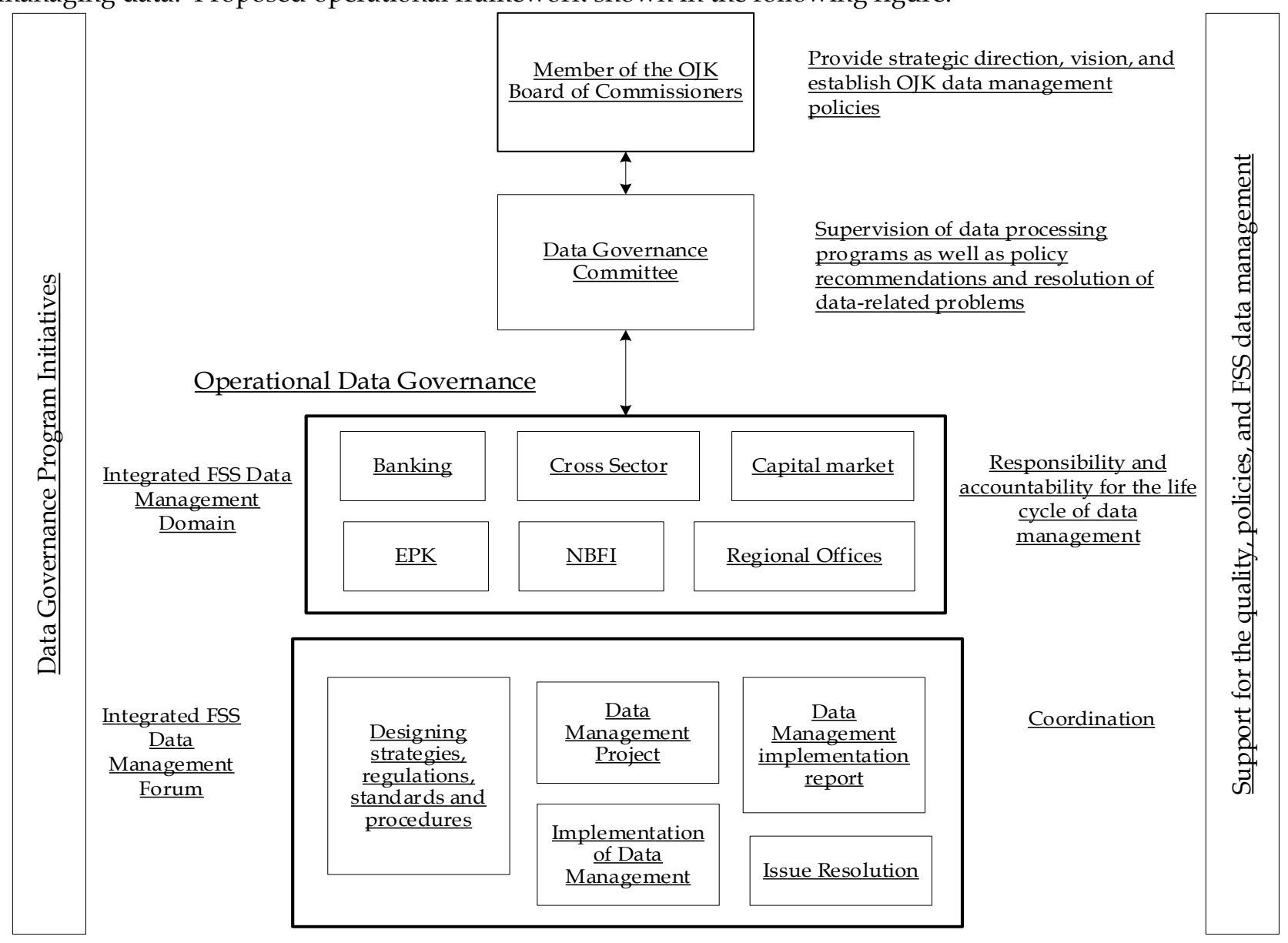

Figure 7. Operational Framework for Integrated FSS Data Governance

FSA Board of Commissioners ratifies regulations must be obeyed by third parties and internally. Currently, FSA has begun to formulate provisions related to integrated FSS data management as the legal basis for data governance activities. The drafting of these provisions can support the implementation of the vision, mission, objectives, principles and data management policies. Data management as part of FSA-RBSI has several projects. However, the establishment of data governance structures and data management provisions has not been implemented. Roadmap of integrated FSS data-governance needs to be adjusted and equipped with standard operating procedures (SOP) in order to explain technical implementation of master data management, reference data, metadata, data integration, and use of FSS data as shown in table 2 below:

Table 2. Integrated FSS Data governance Roadmap

\begin{tabular}{|c|c|c|c|c|c|}
\hline No & Aspects of Data Governance & 2019 & 2020 & 2021 & 2022 \\
\hline 1 & Establishment of data governance structures & & & & \\
\hline 2 & $\begin{array}{l}\text { Preparation of PDK, SEDK and SOP for data man- } \\
\text { agement }\end{array}$ & & & & \\
\hline 3 & Standardization of reference and master data & & & & \\
\hline 4 & Metadata standardization & & & & \\
\hline 5 & Implementation of master data management & & & & \\
\hline 6 & Implementation of data quality management & & & & \\
\hline 7 & $\begin{array}{l}\text { Gradual implementation of enterprise data warehouse } \\
\text { and big data analytics }\end{array}$ & & & & \\
\hline
\end{tabular}


GDST does not have a specific program nor a team assigned to carry out a cultural change program for data management. However, GDST always tries to provide education and socialization to show the importance of data management. GDST also recommends the using of reference data or metadata in application development to reduce the work of remapping data structures at data integration process. Proper handling of issue management is evidence that data has been managed adequately. Currently, there is no specific procedure for resolving data-related problems. Incidental meetings are a common means of discussing solutions that occur in each unit. Problems that cannot be resolved at a lower level are submitted gradually to a higher level in the FSA.

Several provisions related to data management are made following best practices and standards such as Control Objective for Information and related Technology (COBIT), The Open Group Architecture Framework (TOGAF 9), International Organization for Standardization (ISO 20000, ISO 27001, ISO 22301, ISO 27031), Information Technology Infrastructure Library (ITIL). These provisions include information system service management, penetration testing, confidential information management, information system management, application development procedures, and archive management.

The existing provisions do not cover the areas of reference data management, master data, metadata, data modeling, data integration and interoperability, data warehousing, business intelligence, big data and data analytics. Preparation and approval of changes to the business glossary are carried out together with other related units. GDST is responsible for updating or changing the business glossary under their area. In 2019 the FSA has created a data dictionary so that it can integrate commercial banks and finance companies data. The data dictionary has been submitted to DPSI and GPSI as a reference in developing information system applications.

GDST provides a suggestion that the enterprise data model can be adopted in the information system application development process. However, for applications that have been running and have not been able to make changes to the data model, the operations will continue using the existing data model. Besides that, development and termination of the application is carried out in the information system technical forum. In order to be in line with FSA's information system technology strategy and policies, the Information Technology Committee provides recommendations on priorities for information system technology projects.

Currently there has been no effort to assess the losses suffered by FSA due to insufficient data to support FSA's duties and functions. The activities of controlling the FSS data governance program are intended to provide adequate procedures so they can guarantee data quality, data integrity, data reliability, and system security. Both developments and obstacles to the implementation of data management projects are reported regularly through board seminars attended by members of the FSA Board of Commissioners. Discussions on other strategic issues can also be done through the FSA-RBSI forum or other informal forums. Based on the analysis has been done, an integrated FSS data governance framework is developed based on the model from DAMA (2017) as follows: 
The definition of integrated FSS data governance is the exercise of authority, control, and decision-making that is included in planning, operational and controlling activities of FSS data management so that it can be utilized for the benefit of OJK

- Manage FSS Data in an integrated manner; $\quad$ Integrated FSS Data Governance Objectives:

- Defining, approving, communicating, and implementing the principles, policies, procedures, matrices, tools, and responsibilities for managing FSS data;

- Monitor and provide guidance on policy compliance, data usage, and data management activities.

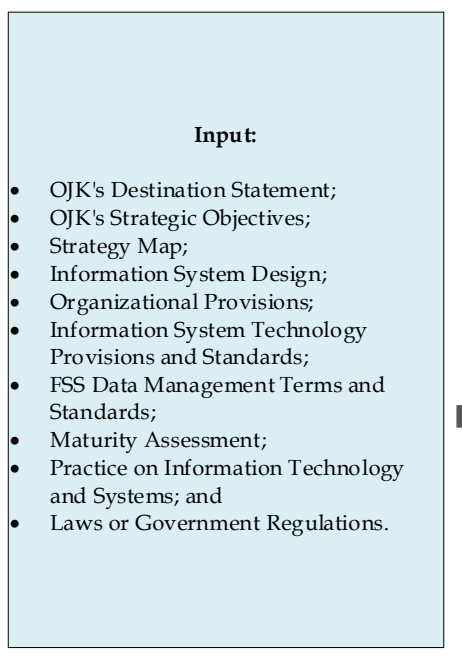

Supplier:

- Members of the OJK Board of Commissioners:

- Information System Design and Construction Task Force;

- Data Owner Work Unit for Banking, Capital Market and NBFI Supervision;

- OJK HR Management Work Unit (DOSM)

- Information System Management and Application Developer Work Unit (DPSI and GPSI);

- OJK Cultural Transformation Program Work Unit (DMSP)

- Data Management Work Unit (DIFB, DSIN, DSIM, GDST);

- Government.

\section{Business Drivers}

Activities:

A. Defines data governance in an organization

1. Develop a data governance strategy;

2. Carry out a readiness assessment;

3. Doing discovery and business alignment, and

4. Develop organizational touch points.

B. Define a data governance strategy

1. Define the operational framework:

2. Develop goals, principles, and policies;

3. Guarantee data management projects;

4. To tie in the management of change;

5. Tying into issue management; and

6. Assess compliance.

C. Implementing data governance

1. Provide support for data-related standards and procedures

2 Develop a business glossary;

3. Coordinating with the architectural group; and

4. Provide support for the assessment of data.

D. Embedding data governance

Participants:

- Members of the OJK Board of Commissioners;

- Data Governance Committee

- Information System Design and Construction Task Force

- Integrated FSS Data Management Forum

- Data Owner Work Unit for Banking, Capital Market and NBFISu pervision;

- OJK HR Management Work Unit (DOSM);

- Information System Management and Application Developer Work Unit (DPSI and GPSI);

- OJK Cultural Transformation Program Work Unit (DMSP)

- Data Management Work Unit (DIFB, DSIN, DSIM, GDST);

- Government.
Output:

Integrated FSS Data Management Strategy; Integrated FSS Data Governance Strategy Roadmap;

Integrated FSS Data Governance Policies and Standards;

Integrated FSS Data Management Standard Operating Procedure
Integrated FSS Data Governance Operational Framework;

Business Glossary;

- Data Governance Scorecard; and

Data Management

Maturation.

Consumer::

- Data Owner Work Unit for Banking, Capital Market and NBFISupervision:

- Data Management Work Unit (DIFB, DSIN, DSIM, GDST);

- Integrated FSS Data Management Forum

- Information System Management and Application Developer Work Unit (DPSI and GPSI);

- OJK Cultural Transformation Implementing Unit (DMSP)

\section{Technical Drivers}

\begin{tabular}{|c|c|c|}
\hline $\begin{array}{l}\text { - Clear Message; } \\
\text { - } \text { Contact List; } \\
\text { - Logo. }\end{array}$ & $\begin{array}{l}\text { Tools: } \\
\text { - Websites; } \\
\text { - Wusiness Glossary Tools; } \\
\text { - Dorkflow Tools; } \\
\text { - Data Governance Scorecard. }\end{array}$ & $\begin{array}{l}\text { Matrix: } \\
\text { - Compliance with rules and policies; } \\
\text { - Value; } \\
\text { - Effectiveness; } \\
\text { - Continuity. }\end{array}$ \\
\hline
\end{tabular}

\section{Figure 8. Integrated FSS Data Governance Framework}

\section{CONCLUSIONS, LIMITATIONS, AND SUGGESTIONS}

Due to the large number of involvement various parties, systems, and the complexity of the process in managing FSA data, the design of integrated FSA data-governance (that is built based on the model from DAMA) is needed to overcome data management problems in the FSA. Problems in managing FSS data in FSA are caused by data management policies, operational processes, human resources, and technology. An integrated FSS data-governance framework based on DAMA model (2017) able to provide guidance in shaping strategies, determining operational activities, and exercising control over FSS data management in FSA. Thus, various parties in FSA will act in line with the strategy that has been developed. The lack of 
research references using the model from The Data Management Association (2017) opens up opportunities for further research. Further research needs to replicate this research with different contexts, locations, and cultures to enrich references in building data governance programs.

\section{REFERENCES}

Al-Ruithe, M., Benkhelifa, E., \& Hameed, K. (2019). A systematic literature review of data governance and cloud data governance. Personal and Ubiquitous Computing, 23(5), 839-859.

B Romney, M. (2018). Accounting information systems: Pearson Education Limited.

Cheong, L. K., \& Chang, V. (2007). The need for data governance: a case study. ACIS 2007 Proceedings, 100.

Jim, C. K., \& Chang, H.-C. (2018). The current state of data governance in higher education. Proceedings of the Association for Information Science and Technology, 55(1), 198-206. doi:https://doi.org/10.1002/pra2.2018.14505501022

Ladley, J. (2019). Data governance: How to design, deploy, and sustain an effective data governance program: Academic Press.

Panian, Z. (2010). Some practical experiences in data governance. World Academy of Science, Engineering and Technology, 62(1), 939-946.

Weber, K., Otto, B., \& Österle, H. (2009). One size does not fit all---a contingency approach to data governance. Journal of Data and Information Quality (JDIQ), 1(1), 1-27.

Were, V. E. (2016). An Assessment of Data Governance at Kenya Health Professionals Regulatory Authorities. University of Nairobi, 